\title{
Investigating and treating fecal incontinence: When and how
}

\author{
Adriana Lazarescu MD FRCPC ${ }^{1}$, Geoffrey K Turnbull MD FRCPC ${ }^{2}$, Stephen Vanner MD FRCPC ${ }^{1}$
}

\begin{abstract}
A Lazarescu, GK Turnbull, S Vanner. Investigating and treating fecal incontinence: When and how. Can J Gastroenterol 2008;23(4):301-308.

Fecal incontinence is a common disorder in our aging population and can have profound effects on patient's well-being. The present review examines the current understanding of fecal incontinence and provides a practical approach to the investigation and management of this condition. A special emphasis is placed on specialized testing, focusing on indications and impact on guiding management.
\end{abstract}

Key Words: Anal ultrasound; Anorectal manometry; Fecal incontinence

Tecal incontinence is a common condition and has a major - impact on a patient's physical and psychological well-being. It is estimated that between $0.8 \%$ and $15 \%$ of the general population experiences fecal incontinence at least once per month (1-3). The prevalence is even higher in patients older than 65 years of age (11\% to $15.2 \%)$ (4) and in those who are institutionalized (20\% to $46 \%$ ) $(5,6)$. In general, fecal incontinence is defined as the continuous or recurrent uncontrolled passage of fecal material (more than $10 \mathrm{~mL}$ ) for at least one month in an individual older than three years of age $(7,8)$. Fecal incontinence can be further subdivided into minor and major categories. Minor incontinence consists of the inadvertent escape of flatus or partial soiling of undergarments with liquid stool, while major incontinence involves involuntary excretion of feces.

As the Canadian population ages, the number of people with fecal incontinence will certainly increase. Aside from taking a medical history and performing a physical examination, there are a variety of investigations that can be undertaken to better understand the pathophysiology of a patient's fecal incontinence. Unfortunately, most of these modalities, such as anal ultrasound and anorectal manometry, are only available in a few tertiary medical centres in Canada. The aim of the present article is to provide a general approach to treatment of patients with fecal incontinence and an understanding of the role of specialized testing. The latter discussion focuses on the most clinically practical tests, anorectal manometry and anal ultrasound, and examines their role in enhancing the diagnosis and management of fecal incontinence.

\section{PHYSIOLOGY OF FECAL CONTINENCE}

The human body combines several voluntary and involuntary mechanisms to achieve fecal continence (Figure 1 and Table 1). The rectum, together with the puborectalis muscle and the internal and external sphincter muscles, controls the passage of stool through the anus.

\section{Épreuves diagnostiques et traitements pour l'incontinence fécale : Quand et comment}

\begin{abstract}
L'incontinence fécale est un trouble répandu chez notre population vieillissante et peut grandement nuire au bien-être des patients. La présente synthèse fait un survol de la compréhension actuelle du phénomène de l'incontinence fécale et propose une approche pratique aux épreuves diagnostiques et à la prise en charge de cette affection. Les auteurs mettent particulièrement l'accent sur les épreuves plus spécialisés et sur l'orientation de la prise en charge.
\end{abstract}

The rectum can accommodate up to $300 \mathrm{~mL}$ in volume before intraluminal pressure increases and a feeling of urgency develops. When an individual is not defecating, the rectum is compliant, receiving increasing amounts of stool volume while maintaining a constant intraluminal pressure. Three distinct semilunar mucosal folds or valves may also play a role in preventing movement of feces toward the anus.

The anal canal is ringed by the internal and external anal sphincter muscles. The internal anal sphincter (IAS) consists of a thickened continuation of the circular smooth muscle layer of the rectum and is innervated by the enteric nervous system and both sympathetic and parasympathetic nerves (Figure 1). It is tonically contracted and accounts for $80 \%$ to $85 \%$ of the anal canal resting pressure (9). The IAS relaxes transiently in response to rectal distension and this relaxation reflex, mediated by enteric nerves, is not under voluntary control. The external anal sphincter (EAS) consists of a striated muscle with somatic innervation from the pudendal nerve (S2, S3 and S4). The EAS represents the voluntary component of fecal continence. Contraction of this muscle approximately doubles the pressure in the anal canal, but this can only be maintained for a few minutes. A spinal reflex causes the EAS to contract during sudden increases in intra-abdominal pressure, such as coughing, thereby helping to maintain continence $(10,11)$.

The puborectalis muscle is another component of voluntary control of fecal continence (Figure 1). It is a striated muscle with somatic innervation from the pelvic branches of the S3 and S4 pudendal nerves. The puborectalis muscle wraps around the rectum and inserts on the symphysis pubis. It thus creates the anorectal angle (normally $60^{\circ}$ to $105^{\circ}$ ) which further slows the progress of stool to the anal canal. The puborectalis muscle functions with both tonic contraction and voluntary control (12). The EAS and puborectalis are unique skeletal muscles in that they both have tonic activity even at rest, thus allowing the tonically contracted EAS to provide $15 \%$ to $20 \%$ of the

${ }^{1}$ Gastrointestinal Diseases Research Unit, Queen's University, Kingston, Ontario; ${ }^{2}$ Dalhousie University, Halifax, Nova Scotia

Correspondence: Dr Stephen Vanner, Queen's University, Hotel Dieu Hospital, Sydenham 4, 166 Brock Street, Kingston, Ontario K7L 5G2.

Telephone 613-544-3310,fax 905-829-0429, e-mailvanners@hdh.kari.net

Received and accepted for publication July 15, 2008 


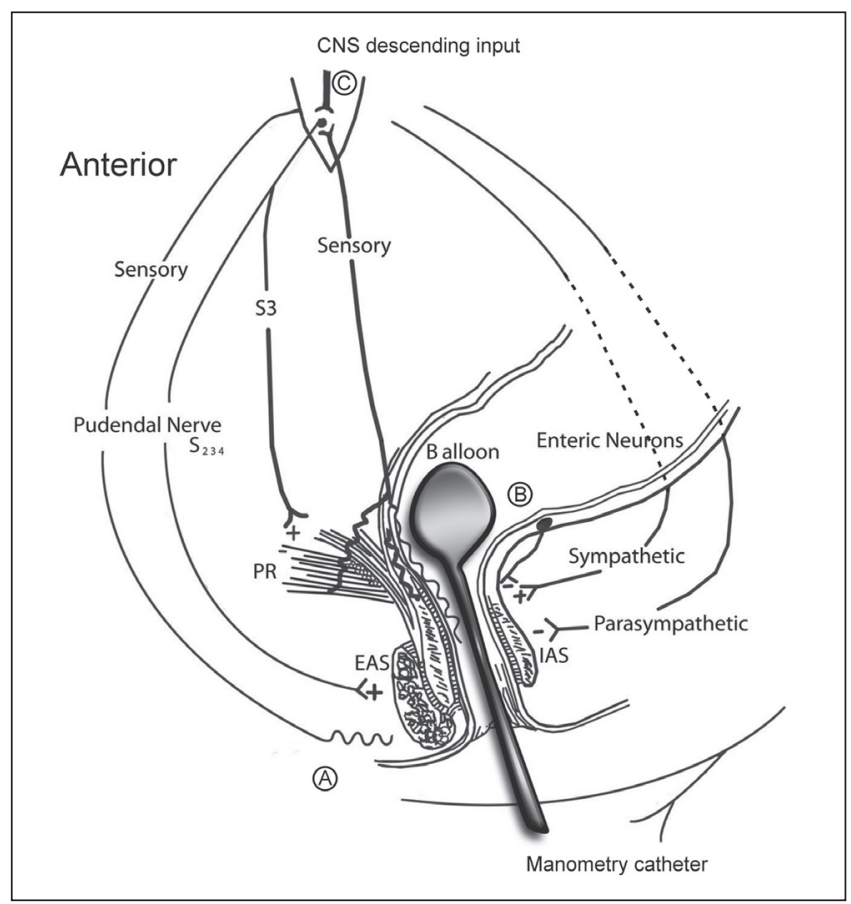

Figure 1) Sagittal view of the anorectal sphincter. Balloon is attached to a manometry catheter with pressure ports within the rectum and anal canal. Pudendal and autonomic nerves originate from nuclei within the spinal cord. Enteric nerves are found within the myenteric plexus in the wall of the rectum. Circled A: Reflex evoked by pin prick of perianal skin; Circled B: Balloon distention evoked reflex contraction of the external anal sphincter (EAS) mediated by sensory nerves and pudendal nerve and inhibition of the internal anal sphincter (IAS) mediated by activation of enteric neurons; Circled C: Reflex contraction of the EAS in response to voluntary squeeze of muscle activated by descending pathways from the central nervous system (CNS). PR Puborectalis muscle; + Excitatory neurotransmitter; - Inhibitory neurotransmitter

resting tone of the anal sphincter. These muscles only completely relax during defecation straining.

As stool accumulates in the rectum, it leads to progressive rectal distension until reflex relaxation of the IAS is triggered and the patient develops the urge to defecate. If the patient chooses to defecate, they straighten the anorectal angle by squatting or sitting and abdominal pressure rises due to straining. The pelvic floor then descends and the rectum contracts. The tonic activity of the EAS is inhibited and the EAS relaxes. Together, these events lead to evacuation of the rectal contents. If the patient chooses not to defecate, they increase contraction of the EAS to maintain continence. Some stool may also move slightly more proximally in the colon, thereby reducing the pressure in the rectum as well as the urge to defecate. As mentioned, the enhanced contraction of the EAS can only be maintained for a short period of time and then the urge to defecate returns, unless the rectum accommodates.

\section{Causes of fecal incontinence}

The major factors necessary for fecal continence (Table 1) are an enteric content that is substantially firm and bulky, a passively distensible, capacious and evacuable reservoir and an effective barrier to outflow. Therefore, changes in the quantity
TABLE 1

Mechanisms of fecal continence

\begin{tabular}{ll}
\hline Mechanism & Role in continence \\
\hline Rectal sensation & $\begin{array}{c}\text { Perception of 'call to stool' triggers dynamic } \\
\text { responses to maintain continence }\end{array}$ \\
$\begin{array}{cc}\text { Internal anal sphincter tone } \\
\text { External anal sphincter and } \\
\text { puborectalis muscle tone }\end{array}$ & $\begin{array}{c}\text { Maintains normal anal canal closure } \\
\text { during internal anal sphincter relaxation }\end{array}$ \\
Rectal accommodation & Allows rectal filling without high intrarectal \\
& pressures that may threaten continence \\
\hline
\end{tabular}

and/or quality of stool presented to the sphincter, the inability of the rectum to accommodate, damage to the anal sphincter mechanism and/or an impaired sensation can result in fecal incontinence. As a result, common causes of fecal incontinence include diarrhea, fecal impaction with overflow, impaired rectal storage, loss of rectal sensation to distension, and isolated or combined weakness/impairment of the IAS, EAS and puborectalis muscle. Frequently, it is a combination of more than one of these mechanisms (eg, new onset diarrhea in a patient with pre-existing anal sphincter dysfunction that was subclinical in its expression). Table 2 lists the major causes of fecal incontinence.

\section{SPECIALIZED TESTING}

Anorectal manometry and anal ultrasound are the most useful tests outside of research protocols to investigate fecal incontinence. Other tests include defecography, balloon expulsion, saline infusion, electromyography and pudendal nerve terminal motor latency. These tests are not widely available and are only recommended in highly selected patients.

\section{Anorectal manometry and sensory testing}

Anorectal manometry assesses the neuromuscular function of the rectum and anal canal. It provides an objective assessment of integrity of the anal sphincter muscles (IAS and EAS), and the neuromuscular motor and sensory innervation (Figure 1).

With the patient lying in the left lateral position with knees and hips bent at $90^{\circ}$, a digital rectal examination is performed. Either a solid-state or water-perfused calibrated probe is then inserted into the rectum. The patient is allowed 5 min to relax and achieve steady baseline recordings before measurements are obtained.

Resting sphincter pressure is the difference between the intrarectal pressure and the maximum anal sphincter pressure at rest (Figure 2). The latter is an average of the values obtained as the probe is pulled through the anal canal, either by station pullthrough or slow/rapid pull-through, providing measurements at different distances from the anal verge. Resting pressures (of approximately 80\%) largely reflect the smooth muscle activity of IAS, which is tonically active. False elevations can be seen if the patient is not fully relaxed because an additional component of pressure from the voluntary contraction of the EAS will also be measured (13).

Maximum squeeze pressure is the difference between the intrarectal pressure and the highest pressure that is recorded at any level within the anal canal as the patient is asked to squeeze the anus. Squeeze pressures measure EAS function and reflect combined cognitive, neural and muscle components (Figure 2C) (13). 
TABLE 2

\section{Causes of fecal incontinence}

\begin{tabular}{|c|c|}
\hline \multicolumn{2}{|l|}{ Structural abnormalities } \\
\hline Anal sphincter muscles & Obstetrical injury, hemorrhoidectomy, anal dilation, radiation, inflammatory bowel disease \\
\hline Rectum & Prolapse, hypersensitivity/hyposensitivity, neoplasms, congenital abnormalities, excessive perineal descent \\
\hline Puborectalis muscle & Trauma, obstetrical injury \\
\hline Pudendal nerve & Surgical injury, excessive perineal descent \\
\hline $\begin{array}{l}\text { Central nervous system, spinal cord, } \\
\text { autonomic nervous system }\end{array}$ & $\begin{array}{l}\text { Spinal cord injury, head injury, stroke, back surgery, diabetes mellitus, multiple sclerosis, tabes dorsalis, cauda } \\
\text { equina injury or tumour }\end{array}$ \\
\hline \multicolumn{2}{|l|}{ Functional abnormalities } \\
\hline Anorectal sensation & Obstetrical injury, central nervous system/autonomic nervous system injury, diabetes mellitus \\
\hline Fecal impaction & Dyssynergic defecation \\
\hline \multicolumn{2}{|l|}{ Stool characteristics } \\
\hline Volume and consistency & Inflammatory bowel disease, irritable bowel syndrome, medications, infections \\
\hline Irritants & Bile salt malabsorption, laxatives \\
\hline Hard stools and retention & Dyssynergic defecation, fecal impaction, medications \\
\hline \multicolumn{2}{|l|}{ Other } \\
\hline Physical mobility and cognitive function & Aging, disability, dementia, sedation \\
\hline Psychosis & Willful soiling \\
\hline Medications (see text) & Laxatives, anticholinergics, antidepressants, caffeine, muscle relaxants \\
\hline Food intolerance (see text) & Lactose, fructose, sorbitol \\
\hline
\end{tabular}

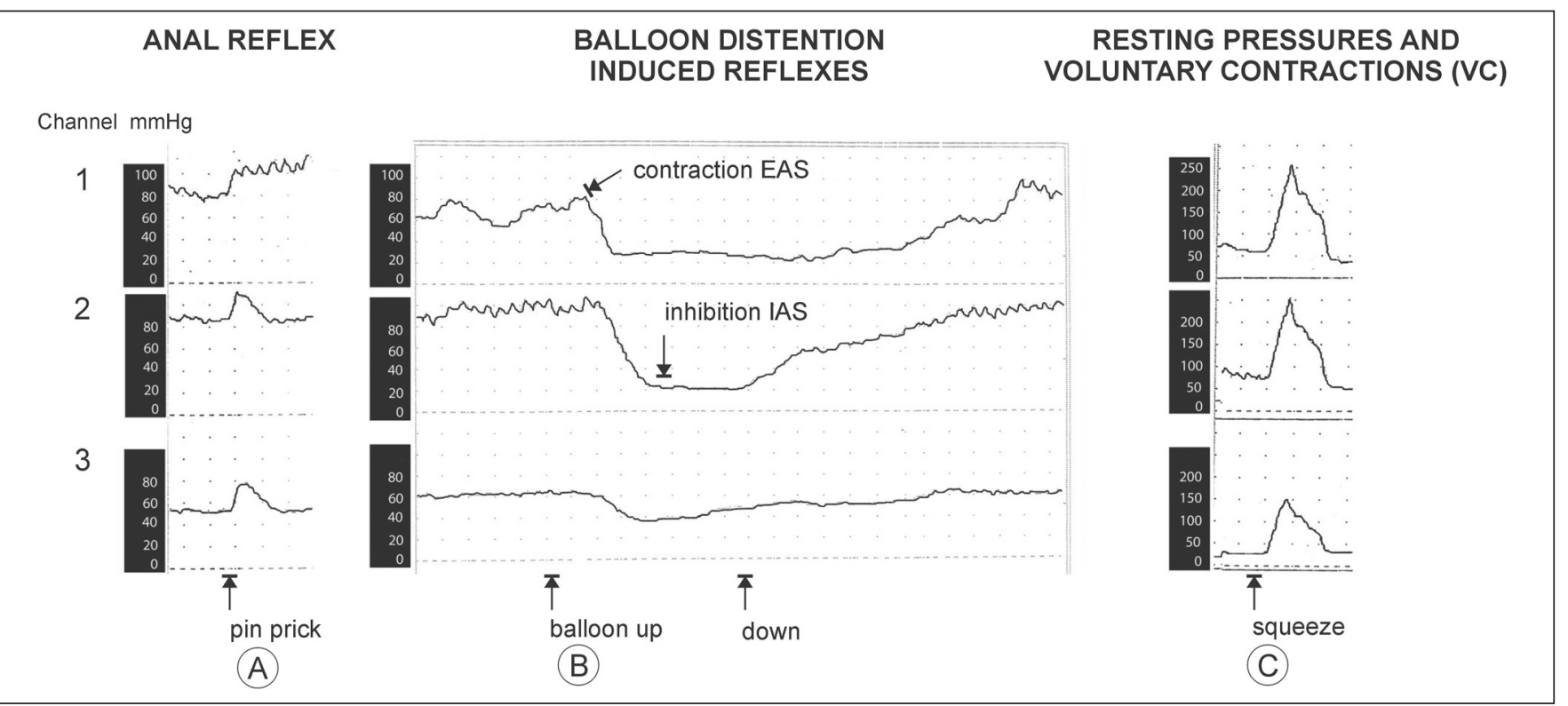

Figure 2) Representative manometry tracings evaluating the integrity of the anorectal sphincter. Circled letters $\mathrm{A}, \mathrm{B}$ and $\mathrm{C}$ correspond to neural reflexes shown in Figure 1. Left panel Anal reflex is evoked by stimulation of perianal skin by pin prick and tests the integrity of sensory and pudendal nerves and the integrity of the external anal sphincter (EAS). Middle panel Resting pressures ( $\mathrm{mmHg}$ ) in the anal canal result from tonic activity of smooth muscle in the internal anal sphincter (IAS) (80\% to 85\%) and tonic activity in the EAS (15\% to 20\%). Balloon distention (arrows) in the rectum evokes blended responses from reflex contraction of the EAS (initial brief pressure increase in channel 1 due to activation of pelvic visceral sensory nerves and reflex contraction of the sphincter mediated by the pudendal motor nerves) and inhibition of the IAS (prolonged pressure decrease mediated by the release of nitric oxide from enteric inhibitory nerves). Right panel Voluntary contraction of the external sphincter muscle tests cognitive ability to contract sphincter, descending spinal neural pathways, pudendal nerves and integrity of the EAS muscle

The anocutaneous reflex represents the response to pin prick stimulation of the perianal skin evoking a reflex contraction of the EAS. It tests the integrity of somatic sensory nerves and the pudendal motor nerves (Figures 1 and 2). The cough reflex represents the increase in anal sphincter pressure during an abrupt change in intra-abdominal pressure (13).

Rectal sensation is assessed by placing a balloon in the rectum and slowly inflating it with air (Figure 1). Three sensory thresholds have been reported to increasing volumes of distention: the first detectable sensation; the sensation of urgency to defecate (desire to defecate); and the sensation of discomfort or pain (maximum tolerable volume) (12). The sensory nerves evoked by distention exist within the rectal wall and pelvic fascia.

Rectal compliance is typically assessed by rapidly inflating the intrarectal balloon with $50 \mathrm{~mL}$ of air. With balloon distention, 
the IAS should relax (Figure 2) due to activation of the rectoinhibitory reflex (ie, stimulation of inhibitory enteric nerves which release nitric oxide and relax the tone of the internal sphincter smooth muscle [Figure 1]) (13).

It is important to recognize that anorectal manometry measurements are only semiquantitative. Normal anal canal pressures vary within the general population (14). Men generally have higher pressures than women and pressures decrease with age in both sexes (15). Interestingly, sphincter pressures vary significantly in both continent and incontinent patients. Resting anal sphincter pressures also vary based on the measurement technique. Rapid pull-through pressures tend to be higher than station pull-through values $(16,17)$. Mean station pull-through resting anal canal pressures vary between $49 \mathrm{mmHg}$ and $58 \mathrm{mmHg}$ in women and from $49 \mathrm{mmHg}$ to $66 \mathrm{mmHg}$ in men $(12,15-17)$. Approximately $80 \%$ of this pressure is due to tonic IAS contraction (7).

Sensitivity and specificity of maximal squeeze pressures for discrimination of incontinent patients from continent patients and controls varies between $60 \%$ and $92 \%$, and $67 \%$ to $97 \%$, respectively $(18,19)$. Mean station pull-through maximal squeeze anal canal pressures vary between $90 \mathrm{mmHg}$ and $159 \mathrm{mmHg}$ in women and from $218 \mathrm{mmHg}$ to $238 \mathrm{mmHg}$ in men (20-22).

\section{Anal ultrasound}

Anal ultrasound can be used to image the internal and external anal sphincter muscles and the puborectalis muscle. The patient takes an enema to clear the rectum and after a digital rectal examination, a rigid rotating probe with a $360^{\circ}$ radius and an ultrasound frequency of between $5 \mathrm{MHz}$ and $16 \mathrm{MHz}$ is introduced into the rectum. The probe is then slowly withdrawn so that the pelvic floor and subsequently the sphincter complex are seen. The diameter of the probe is small enough to minimize any distortion of the anal canal. Scanning with the patient prone has been suggested to yield better visualization of the anterior wall of the EAS (23). Recent advancements have allowed for three-dimensional reconstruction of the images.

Anal ultrasound assesses muscle thickness and integrity and can identify scarring, loss of muscle tissue or other local pathology. IAS defects tend to be identified more reliably than EAS defects. Interpretation of EAS images is more subjective and operator-dependent due to anatomical variations in the EAS and the normal asymmetry of the muscle. Interobserver variability can play a role in the interpretation of anal ultrasound images $(24,25)$.

Defects in the IAS are accompanied by lower resting pressures, while defects in the EAS are associated with lower maximal anal squeeze pressures. In addition, the size of the EAS defect inversely correlates with the maximum squeeze pressure (26-28).

\section{APPROACH TO THE PATIENT WITH FECAL INCONTINENCE}

A thorough history and physical examination can provide important clues to the etiology of fecal incontinence (Table 3). Most patients are embarrassed by incontinence and some will not admit to the problem unless asked directly or may refer to their difficulty as 'diarrhea'. The amount, pattern and duration of incontinence need to be elicited, as well as any history of conditions listed in Table 1. Asking a patient to keep a symptom diary can help in clarifying the bowel habit. It is also important to explore the impact of the fecal incontinence on the patient's quality of life because this disorder can result in patients being 'housebound' and be associated with marked anxiety and/or decreased mood.

A recent onset of incontinence without any change in bowel habit makes a diagnosis of neurological disease much more likely. Investigation for a central nervous system cause or malignant disease of the colon is critical to pursue because an early diagnosis for these conditions often results in a better outcome. Nocturnal stool incontinence often implies an underlying bowel disorder, although diabetes can also present with this feature. Some patients report incontinence but only have 'seepage' of stool. If the seepage usually occurs after defecation, this indicates either weakness of resting anal sphincter tone, fecal impaction or problems with incomplete rectal emptying during defecation (29).

Often the fecal incontinence complaint can be precipitated by another problem that causes loose stool resulting in incontinence. These patients often have an excellent outcome if the underlying cause of the loose stool can be identified and treated. The presence of urinary incontinence should also be determined. Patients with impaired anal sphincter contraction, impaired nerve function or both will often have associated urinary incontinence complaints that may predate the fecal incontinence.

Some dietary factors can also increase anal seepage (often also associated with pruritus ani) and excess coffee consumption is commonly implicated. Coffee can affect bowel function, often triggering an urge to defecate in $29 \%$ of subjects surveyed (30), but the mechanism of this response has not been consistently found in anorectal research studies $(31,32)$. It is important to ask about coffee intake or other caffeinated beverages, as well as citrus juices, milk and foods such as popcorn and nuts, which may also be triggers for rectal seepage in susceptible individuals. Diet candy, sugarless gum and lozenges should be asked about and eliminated if the patient is taking them. A simple dietary exclusion of the offending food or drink for one to two weeks will clarify the contribution of these foods to the seepage. Attention to perianal skin cleanliness without excessive rubbing with tissue paper helps to also decrease secondary injury to the skin from rubbing and scratching and keeps the seepage to a minimum.

A careful inventory of drug therapy should be compiled because drugs can also contribute to new-onset diarrhea. Inquiries regarding over-the-counter medications including vitamin supplements, calcium supplements and herbal remedies must also be made. Many calcium supplements also contain magnesium salts that will increase diarrhea. Fecal incontinence is often greatly improved or resolved by just removing the offending agent. Vitamin $\mathrm{C}$ in large quantities can produce diarrhea as a side effect and is often not recognized by a person who takes vitamin $\mathrm{C}$ supplements daily.

One of the more common presentations of fecal incontinence is in women 50 to 60 years of age who have had their gallbladder removed. This type of incontinence is always associated with looser bowel motions and the restoration of the stool to a more solid consistency with a trial of cholestyramine or loperamide, which resolves or improves the incontinence.

Another typical presentation is the gradual development of fecal incontinence in a woman many years after having children. This can be more abrupt if there is an associated change in bowel pattern. Risk factors for anal sphincter injury during vaginal delivery are greatest for the mother when having her 
first baby. Other risk factors include the use of instrumentation for the delivery; a prolonged second stage of labour; the baby's weight is over $3 \mathrm{~kg}$; and if the baby was in the occiput posterior presentation (33).

\section{Highlights for the physical examination}

The general physical examination should include a screening examination of the neurological system. Particular attention must be given to the lower extremities when looking for evidence of lower or upper motor neuron changes. Checking the lower extremities for loss of vibration or position sense can also indicate vitamin $\mathrm{B}_{12}$ deficiency, and causes for this should be ruled out (especially terminal ileal disease which, regardless of cause, will result in diarrhea). It is crucial to test the sensation of the perineum because the S2 to S4 nerves are only represented in the perianal skin. Loss of ankle reflexes with decreased sensation in the S1 dermatome can signal distal spinal cord or cauda equina disease as a cause of the fecal incontinence.

On abdominal examination, looking for evidence of gastrointestinal disease is the main objective. For example, right lower quadrant pain with a suggestion of fullness or a palpable mass is an indication of distal ileal disease, often Crohn's disease. An abdominal mass in an older patient with change in bowel habit (usually looser stool with fecal incontinence) requires exclusion of colonic or rectal tumours. Some patients may have a remote history of radiation treatment and will develop increasing problems with diarrhea and decreased rectal compliance during the years after radiation treatment. These symptoms may progress even 10 years or longer after the original therapy. The presence of diarrhea at the time of the initial radiation therapy is the best predictor of significant colorectal mucosal injury with radiation and of increased likelihood of future radiation enteritis. Microscopic colitis is also a relatively common cause of new onset diarrhea in older patients.

Inspection of the perianal area should include checking for the anocutaneous reflex (anal wink) and completing a digital rectal examination to look for rectal masses and prolapse. The anal wink is performed by gently scratching the anal skin and looking for the reflex anal muscle contraction. The patient should then be asked to bear down as if having a bowel motion to look for perineal descent. Using the ischial tuberosities as reference points, the anal verge should not drop below the plane formed by the tuberosities. If it does, then there is excessive perineal descent. This is associated with distortion of the normal anorectal anatomy which may cause impairment of complete rectal emptying. While the patient is bearing down, there may be evidence of the rectum prolapsing through the anus. Prolapse is often missed if not looked for when the patient is straining. If the history strongly suggests rectal prolapse, then the patient should be asked to strain while in a seated position (usually on the toilet or a commode in the clinic). Next, gentle traction should be applied to the anal verge. If the anal opening gapes with gentle traction, this indicates that resting anal sphincter tone is reduced, which increases the likelihood of anal seepage.

On digital rectal examination, the physician can ask the patient to try to squeeze the examiner's finger; however, this does not correlate well with objective measures of anorectal function $(34,35)$. In particular, EAS defects of less than $90^{\circ}$ defined by endoanal ultrasound, could not be reliably predicted on digital rectal examination, although there was some
TABLE 3

\section{History and physical examination for fecal incontinence}

History

Onset, duration and pattern of symptoms

Stool consistency

Associated symptoms: Urgency, lack of

sensation of stool passage, urinary incontinence

Medical history

Diabetes mellitus, multiple sclerosis, radiation

treatment, dementia

Surgical history

Vaginal delivery (number, complications,

use of forceps, episiotomy, tear)

Hemorrhoidal surgery

Perianal surgery

Bowel resection

Medications Psyllium fibre, antibiotics,

proton pump inhibitors, etc (see text)

Physical examination

Perianal scars, fistulae, fissures, skin irritation

Hemorrhoids, anal skin tags, prolapse

Anocutaneous reflex (anal wink)

Digital rectal examination - resting and squeezing

anal sphincter tone, masses

Sensation intact? (ie, aware of urge to defecate

on rectal examination; anal sensation)

correlation between manometric findings and physical examination findings (36). Sensation of the perianal skin to pinprick should also be tested. This is best performed with a sterile safety pin because it is not as sharp as needles used for injection and can be closed after use and disposed of with minimal risk of a needle-stick injury. Most hospitals can sterilize safety pins for single use and they should be kept in the examination room for easy access.

Investigations are generally directed toward identifying common, potentially reversible causes of fecal incontinence such as diarrhea. Routine laboratory tests and stool cultures are usually ordered. A flexible sigmoidoscopy can rule out structural causes such as a mass, rectal inflammation or fecal impaction. In most cases, it is reasonable to give a trial of medical therapy first. However, in a young person with fecal incontinence due to major trauma there should be a lower threshold to progress to additional testing because these treatments are often unsuccessful. Medical therapy includes bulking agents, such as psyllium fibre (eg, one to two tablespoons of psyllium fibre powder [37]) and antidiarrheal agents, such as loperamide (38), diphenoxylate hydrochloride and atropine sulfate (39). Many treatment trials using antidiarrheal agents fail because the physician does not emphasize to the patient that they need to take these agents before situations known to trigger fecal urgency or incontinence such as meal times. Most patients require daily medication if they are to achieve predictable continence. If diarrhea or urgent bowel motions are worse first thing in the morning, the patient should then take $2 \mathrm{mg}$ to $4 \mathrm{mg}$ of loperamide (or equivalent of diphenoxylate) typically combined with psyllium fibre as soon as they get up in the morning.

\section{The role for specialized testing}

If a patient fails empirical medical management, further investigations can be helpful in the following settings:

1. In patients suspected of having an anal sphincter injury, imaging and measurement of neuromuscular function can determine whether they are candidates for surgical repair; 
2. In patients who are being considered for biofeedback therapy, anorectal manometry is helpful in determining whether they are potential candidates;

3. In patients whose history is out of proportion to objective findings on initial tests and those with potential secondary gain, objective measurement of the function of the anal sphincter and rectum mechanism can clarify whether any deficits are present; and

4. In patients with inflammatory bowel disease who may need surgery that includes an ileal pouch-anal anastamosis, testing the anal sphincter can provide prognostic information about the risk of severe postoperative fecal incontinence.

\section{Suspected anal sphincter injury}

If structural damage to the anal sphincter is suspected, such as the result of previous traumatic vaginal births, it is reasonable to consider referral for anal ultrasound to image the IAS and EAS muscles and determine whether they are still intact. The clinical usefulness of anal ultrasound in diagnosing anal sphincter defects in patients with fecal incontinence has been evaluated in a variety of studies.

Sentovich et al (40) performed anal ultrasound and anorectal manometry on asymptomatic nulliparous and multiparous women, and on women with fecal incontinence. The latter group subsequently underwent sphincteroplasty. Anal ultrasound identified all the sphincter defects found intraoperatively. However, anal ultrasound also falsely diagnosed sphincter injury in $10 \%$ of the asymptomatic nulliparous women with intact anal sphincters.

Sultan et al (41) prospectively assessed the accuracy of anal ultrasound in patients with fecal incontinence by using surgical histology as the gold standard for diagnosing sphincter defects. Preoperatively, patients underwent anal ultrasound, electromyography and manometry. The ultrasonographer and pathologist were blinded to the results of the other investigations. Anal ultrasound correctly identified all the sphincter defects, both in the internal and external sphincters, without any falsepositive results.

Patients with fecal incontinence due to EAS defects can be referred for sphincteroplasty. The efficacy of this procedure has been assessed mostly in studies involving women with obstetric injury to the EAS. Felt-Bersma et al (42) compared pre- and postoperative anal ultrasound results with patients' self-reported symptoms of fecal incontinence. Postoperatively, $72 \%$ of patients had either improvement or resolution of their fecal incontinence and anal ultrasound found improvement or disappearance of anal sphincter defects in $78 \%$ of patients. Symptom improvement correlated with structural changes demonstrated by anal ultrasound. Similar results were noted by Ternent et al (43). In addition, Engel et al (44) found that women who developed fecal incontinence years after delivery derived similar benefit from EAS surgical repair as women who developed fecal incontinence immediately after delivery.

The benefit of adding anorectal manometry to routine investigations for fecal incontinence was assessed by Keating et al (45). Fifty patients with fecal incontinence were studied prospectively in a tertiary care centre. The patients were assessed by two physicians who formulated a diagnosis and treatment plan. The patients then underwent anorectal testing. The additional tests led to a change in diagnosis in $19 \%$ of patients and a change in treatment in $50 \%$ of patients assessed by history and physical examination alone. Similarly, Rao et al (46) found that anorectal manometry provided a better understanding of the underlying pathophysiology of fecal incontinence in individual patients and led to specific interventions.

In the case of IAS defects, delineation of pathology by anal ultrasound allows for an increased understanding of the disease process and suggests treatment with either a supportive medical approach or newer surgical techniques designed to increase resting tone. For example, phenylephrine gel applied to the distal anal canal in patients with a weak IAS and low mean resting anal pressures significantly increased mean resting anal pressure and had improved symptoms compared with placebo (47). This effect was seen starting at a concentration of $30 \%$ phenylephrine and no side effects were reported.

\section{Suspected defecation or sensory disorder}

If a defecation or sensory disorder is in the differential diagnosis for a particular patient, anorectal manometry can be used to assess the sensation, compliance and pressure in the rectum and anal canal, and to predict a response to biofeedback training. Biofeedback therapy is a noninvasive method of cognitively retraining the pelvic floor. It is thought to improve symptoms either by enhancing the patient's ability to perceive rectal distension by increasing the contraction amplitude of the striated voluntary muscles of the pelvic floor or by enhancing the coordination of sensory and muscular components required for continence. If a sphincter defect, rather than just sphincter weakness, is found on anorectal manometry, the patient may still benefit from biofeedback therapy (48). However, if there is a total absence of rectal sensation, rather than decreased sensation, the results of therapy are likely to be poor (49).

The benefit of biofeedback has been evaluated in numerous studies, most of which are small in size and retrospective in design. While most studies show some benefit in fecal incontinence, anywhere between $38 \%$ and 100\% (50-55), a Cochrane database review (56) did not show any reliable improvement in symptoms. In fact, even when a patient's fecal incontinence has been successfully treated, the manometry results often do not improve $(16,57)$.

Rectal sensory deficits are either due to trauma or a systemic disease and appropriate investigations and management should be directed toward such a diagnosis.

\section{Anal ultrasound, anorectal manometry or both}

Anal ultrasound and anorectal manometry are often complementary to each other. They help determine whether the cause of fecal incontinence is structural or functional. Disruption of either or both of the anal sphincter muscles can be diagnosed with anal ultrasound. Manometric findings often concur by measuring decreased resting pressures with IAS defects and decreased squeeze pressures with EAS defects. The size of the EAS defect inversely correlates with the maximum squeeze pressure (26-28). However, a thorough history and physical examination are required first to determine whether a sphincter defect is suspected and to prompt further referral. If a sphincter defect is not suspected, the diagnostic yield of these tests is low.

Anal ultrasound and anorectal manometry can also be useful when they are both normal. Such patients with idiopathic fecal incontinence may benefit from a trial of amitriptyline. Amitriptyline $20 \mathrm{mg}$ orally daily for four weeks significantly improved symptoms in 18 patients based on an 18-point fecal 
incontinence score (58). Manometrically, the anal resting and squeeze pressures were not different before and after treatment. The authors hypothesized that amitriptyline may work by affecting colorectal motility.

\section{CONCLUSION}

Fecal incontinence is a common and distressing symptom in the general population and will likely increase in prevalence with time. It can arise due to a large variety of causes and is often multifactorial. No single test alone can be used reliably to diagnose the etiology of fecal incontinence in a particular patient. Investigative modalities such as anal ultrasound and anorectal manometry are only available in a few centres in Canada.

A thorough history and physical examination often elucidates the cause of fecal incontinence and provides important clues about treatment. Once 'red flags' have been ruled out and reversible causes of diarrhea excluded, many patients respond to empirical medical management. In selected cases, referral for specialized testing can be helpful. Anal ultrasound is useful in assessing for structural sphincter defects and helps predict response to surgical repair. Anorectal manometry provides information on sensory defects, semi-quantitative measurement of the internal sphincter and external sphincter pressures, integrity of neural innervation and may predict response to biofeedback therapy.

\section{REFERENCES}

1. Drossman DA, Li Z, Andruzzi E, et al. US householder survey of functional gastrointestinal disorders. Prevalence, sociodemography, and health impact. Dig Dis Sci 1993;38:1569-80.

2. Thomas TM, Egan M, Walgrove A. The prevalence of fecal and double incontinence. Community Med 1984;6:216-20.

3. Macmillan AK, Merrie AE, Marshall RJ, Parry BR. The prevalence of fecal incontinence in community-dwelling adults: A systematic review of the literature. Dis Colon Rectum 2004;47:1341-9.

4. Roberts RO, Jacobsen SJ, Reilly WT, Pemberton JH, Lieber MM, Talley NJ. Prevalence of combined fecal and urinary incontinence: A community-based study. J Am Geriatr Soc 1999;47:837-41.

5. Barrett JD. Colorectal disorders in elderly people. Br Med J 1992;305:764-6.

6. Chassagne P, Landrin I, Neveu C, et al. Fecal incontinence in the institutionalized elderly: Incidence, risk factors, and prognosis. Am J Med 1999;106:185-90.

7. Drossman DA, Funch-Jensen P, Janssens J. Identification of sub-groups of functional gastrointestinal disorders. Gastroenterol Int 1990;3:159.

8. Thompson WG, Longstreth GF, Drossman DA, Heaton KW, Irvine EJ, Muller-Lissner SA. Functional bowel disease and functional abdominal pain. Gut 1999;45(Suppl 2):II43-7.

9. Frenckner B, Von Euler C. Influence of pudendal nerve block on the function of the anal sphincter. Gut 1975;15:482-9.

10. Kumar D, Waldron D, Williams NS, Browning C, Hutton MR, Wingate DL. Prolonged anorectal manometry and external anal sphincter electromyography in ambulant human subjects. Dig Dis Sci 1990;35:641-8.

11. Sun WM, Read NW, Miner PB. Relation between rectal sensation and anal function in normal subjects and patients with faecal incontinence. Gut 1990;31:1056-61.

12. Fernandez-Fraga X, Azpiroz F, Malagelada JR. Significance of pelvic floor muscles in anal incontinence. Gastroenterology 2002;123:1441-50.

13. Rao SSC, Azpiroz F, Diamant N, Enck P, Tougas G, Wald A. Minimum standards of anorectal manometry. Neurogastroenterol Mot 2002;14:553-9.

14. Loening-Baucke V, Anuras S. Effects of age and sex on anorectal manometry. Am J Gastroenterol 1985;80:50-3.

15. McHugh SM, Diamant NE. Effect of age, gender, and parity on anal canal pressures. Contribution of impaired anal sphincter function to fecal incontinence. Dig Dis Sci 1987;32:726-36.

16. Pedersen IK, Christiansen J. A study of the physiological variation in anal manometry. Br J Surg 1989;76:69-71.
17. McHugh SM, Diamant NE. Anal canal pressure profile: A reappraisal as determined by rapid pull-through technique. Gut 1987;28:1234-41.

18. Felt-Bersma RJ, Klinkenberg-Knol EG, Meuwissen SG. Anorectal function investigations in incontinent and continent patients. Differences and discriminatory value. Dis Colon Rectum 1990;33:479-85.

19. Sun WM, Donnelly TC, Read NW. Utility of a combined test of anorectal manometry, electromyography and sensation in determining the mechanism of "idiopathic" faecal incontinence. Gut 1992;33:807-13.

20. Loening-Baucke V, Anuras S. Anorectal manometry in healthy elderly subjects. Am Geriatr Soc 1984 32:636-9.

21. Read NW, Harford WV, Schmulen AC, Read MG, Santa Ana C, Fordtran JS. A clinical study of patients with fecal incontinence and diarrhea. Gastroenterology 1979 76:747-56.

22. Caruana BJ, Wald A, Hinds JP, Eidelman BH. Anorectal sensory and motor function in neurogenic fecal incontinence. Comparison between multiple sclerosis and diabetes mellitus. Gastroenterology 1991;100:465-70.

23. Frudinger A, Bartram CI, Halligan S, Kamm M. Examination techniques for endosonography of the anal canal. Abdom Imaging 1998;23:301-3.

24. Gold DM, Halligan S, Kmiot WA, Bartram CI. Intraobserver and interobserver agreement in anal endosonography. Br J Surg 1999;3:371-5.

25. Enck P, Heyer T, Gantke B, et al. How reproducible are measures of the anal sphincter muscle diameter by endoanal ultrasound? Am J Gastroenterol 1997;92:293-6.

26. Saclarides TJ. Endorectal ultrasound. Surg Clin North Am 1998;78:237-49.

27. Falk PM, Blatchford GJ, Cali RL, Christensen MA, Thorson AG. Transanal ultrasound and manometry in the evaluation of fecal incontinence. Dis Colon Rectum 1994;37:468-72.

28. Ternent CA, Shashidharan M, Blatchford GJ, Christensen MA, Thorson AG, Sentovich SM. Transanal ultrasound and anorectal physiology findings affecting continence after sphincteroplasty. Dis Colon Rectum 1997;40:462-7.

29. Rao SSC, Ozturk R, Stessman M. Investigation of the pathophysiology of fecal seepage. Am J Gastroenterol 2004;99:2204-9.

30. Brown SR, Cann PA, Read NW. Effect of coffee on distal colon function. Gut 1990;31:450-3.

31. Rao SS, Welcher K, Zimmerman B, Stumbo P. Is coffee a colonic stimulant? Eur J Gastroenterol Hepatol 1998;10:113-8.

32. Sloot C, Felt-Bersma R, West R, Kuipers E. Stimulation of Defecation: Effects of coffee use and nicotine on rectal tone and visceral sensitivity. Scand J Gastroenterol 2005;40:808-13.

33. de Leeuw JW, Struijk PC, Vierhout ME, Wallenburg HCS. Risk factors for third degree rupture during delivery. Br J Obstet Gynecol 2001;108:383-7.

34. Coller JA. Clinical application of anorectal manometry. Gastroenterol Clin North Am 1987;16:17-33.

35. Hallan RJ, Marzouk DE, Waldron DJ, Womack NR, Williams NS. Comparison of digital and manometric assessment of anal sphincter function. Br J Surg 1989;76:973-5.

36. Dobben AC, Terra MP, Deutekom M, et al. Anal inspection and digital rectal examination compared to anorectal physiology tests and endoanal ultrasonography in evaluating fecal incontinence. Int J Colorectal Dis 2007;22:783-90.

37. Bliss DZ, Hans-Joachim J, Savik D, et al. Supplementation with dietary fiber improves fecal incontinence. Nurs Res 2001;50:203-13.

38. Read M, Read NW, Barber DC, Duthie HL. Effects of loperamide on anal sphincter function in patients complaining of chronic diarrhea and fecal incontinence and urgency. Dig Dis Sci 1982;27:807-14.

39. Harford WV, Krejs GJ, Santa Ana CA, Fordtran JS. Acute effect of diphenoxylate and atropine (Lomotil) in patients with chronic diarrhea and fecal incontinence. Gastroenterology 1980;18:440.

40. Sentovich SM, Blatchford GJ, Rivela LJ, Lin K, Thorson AG, Christensen MA. Diagnosing anal sphincter injury with transanal ultrasound and manometry. Dis Colon Rectum 1997;40:1430-4.

41. Sultan AH, Kamm MA, Talbot IC, Nicholls RJ, Bartram CI. Anal endosonography for identifying external sphincter defects confirmed histologically. Br J Surg 1994;81:463. 
42. Felt-Bersma RJ, Cuesta MA, Koorevaar M. Anal sphincter repair improves anorectal function and endosonographic image. A prospective clinical study. Dis Colon Rectum 1996;39:878-85.

43. Ternent CA, Shashidharan M, Blatchford GJ, et al. Transanal ultrasound and anorectal physiology findings affecting continence after sphincteroplasty. Dis Colon Rectum 1997;40:462-7.

44. Engel AF, Kamm MA, Sultan AH, Bartram CI, Nicholls RJ. Anterior anal sphincter repair in patients with obstetric trauma. Br J Surg 1994;81:1231-4.

45. Keating JP, Stewart PJ, Evers AA, Warner D, Bokey EL. Are special investigations of value in the management of patients with fecal incontinence? Dis Colon Rectum 1997;40:896-901.

46. Rao SS, Patel RS. How useful are manometric tests of anorectal function in the management of defecation disorders? Am J Gastroenterol 1997;92:469-75.

47. Cheetham MJ, Kamm MA, Phillips RK. Topical phenylephrine increases anal canal resting pressure in patients with faecal incontinence. Gut 2001;48:356-9.

48. Norton C, Kamm MA. Outcome of biofeedback for faecal incontinence. Br J Surg 1999;86:2259-63.

49. Van Tets WF, Kuijpers JH, Bleijenberg G. Biofeedback treatment is ineffective in neurogenic fecal incontinence. Dis Colon Rectum 1996;39:992-4.

50. Wald A, Tunuguntla AK. Anorectal sensorimotor dysfunction in fecal incontinence and diabetes mellitus: Modification with biofeedback therapy. N Engl J Med 1984;310:1282-7.
51. Heymen S, Jones KR, Ringel Y, Scarlett Y, Whitehead WE. Biofeedback treatment of fecal incontinence: A critical review. Dis Colon Rectum 2001 44:728-36.

52. Whitehead WE, Burgio KL, Engel BT. Biofeedback treatment of fecal incontinence in geriatric patients. J Am Geriatr Soc 1985;33:320-4.

53. McHugh S, Walma K, Diamant NE. Fecal incontinence: A controlled trial of biofeedback. Gastroenterology 1986;90:154-5.

54. Norton C, Chelvanayagam S, Wison-Barnett J, Redfern S, Kamm MA. Randomized controlled trial of biofeedback for fecal incontinence. Gastroenterology 2003;125:1320-9.

55. Solomon MJ, Pager CK, Rex J, Roberts R, Manning J. Randomized, controlled trial of biofeedback with anal manometry, transanal ultrasound, or pelvic floor retraining with digital guidance alone in the treatment of mild to moderate fecal incontinence. Dis Colon Rectum 2003;46:703-10.

56. Norton C, Cody JD, Hosker G. Biofeedback and/or sphincter exercises for the treatment of faecal incontinence in adults. Cochrane Database Syst Rev 2006;3:CD002111.

57. Bharucha AE. Outcome measures for fecal incontinence: Anorectal structure and function. Gastroenterology 2004;126:S90-8.

58. Santoro GA, Eitan BZ, Pryde A, Bartolo DC. Open study of low-dose amitriptyline in the treatment of patients with idiopathic fecal incontinence. Dis Colon Rectum 2000;43:1676-81. 


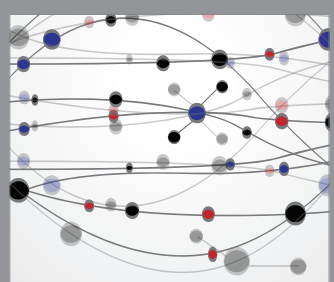

The Scientific World Journal
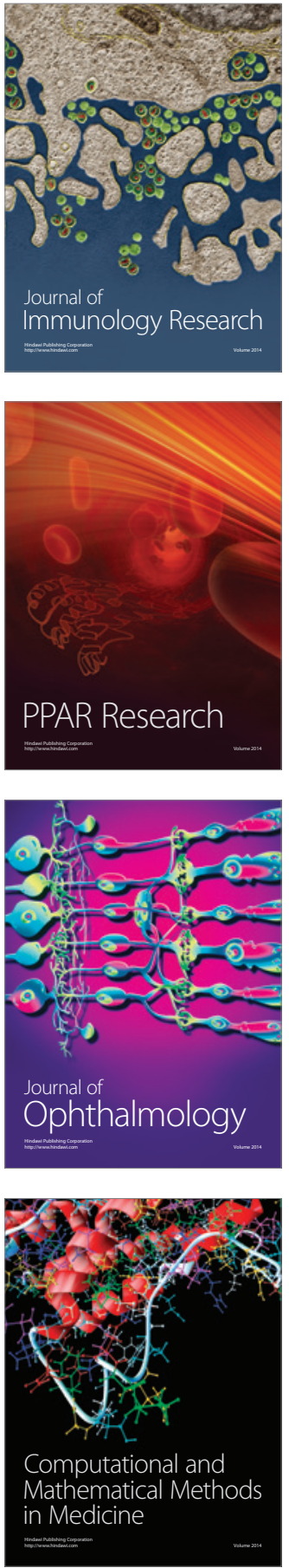

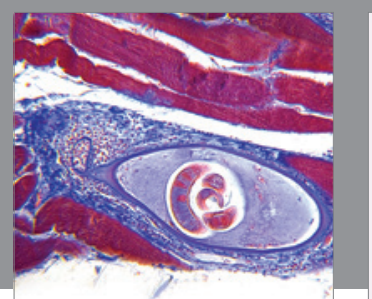

Gastroenterology Research and Practice

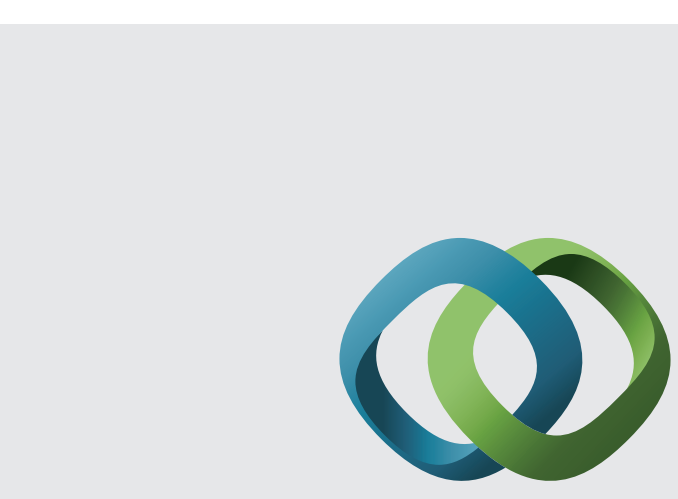

\section{Hindawi}

Submit your manuscripts at

http://www.hindawi.com
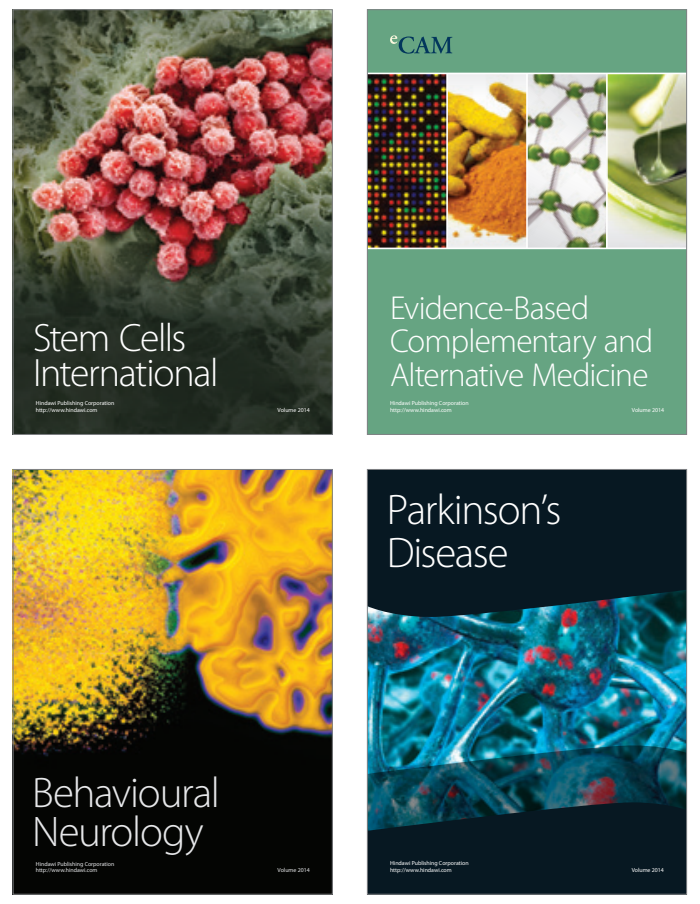
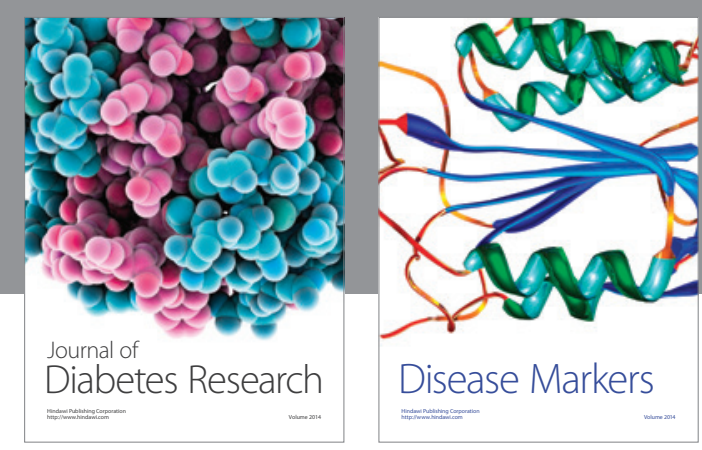

Disease Markers
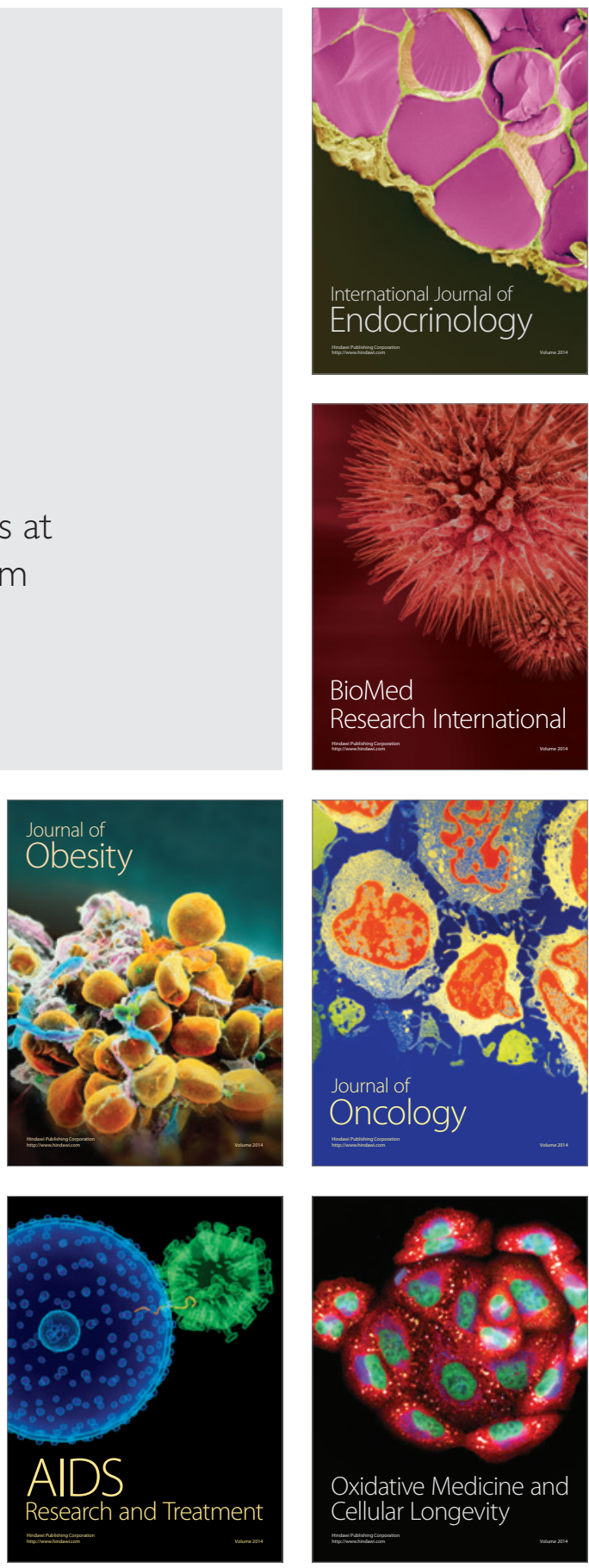